\title{
Estrutura e Dinâmica dos Contratos na Suinocultura de Santa Catarina: Um Estudo de Casos Múltiplos
}

\author{
- Marcelo Miele* \\ - PaUlo D. WaQuil **
}

\begin{abstract}
RESUMO
O desempenho econômico recente da suinocultura brasileira deve-se aos avanços tecnológicos e organizacionais incorporados ao longo das duas últimas décadas, com destaque para a crescente participação dos contratos como forma de coordenação da cadeia produtiva. $O$ objetivo deste trabalho é caracterizar a transação entre os suinocultores e as empresas e cooperativas agroindustriais que abatem e processam suínos em Santa Catarina, bem como a estrutura de incentivos e controles dos contratos que dão suporte a essa transação. Para tanto, utilizou-se uma metodologia de estudo de casos múltiplos, com 19 suinocultores entrevistados e a análise de 12 contratos. Os resultados apontam para a diversidade organizacional e sua dinâmica. A estrutura de incentivos e controles nos contratos aponta para a busca de objetivos econômicos e de eficiência técnica.
\end{abstract}

\section{Palavras-chave}

contratos, coordenação, agronegócio, suinocultura

\begin{abstract}
The economic performance of the Brazilian swine and swine meat production was based on technological and organizational innovations, in which the contracts play an important role in the supply chain coordination. The goal of this research is to characterize the transaction among swine producers and slaughters and meat processors in Santa Catarina, Brazil, and the contract structure of incentives and controls which supports this transaction. The research technique employed is a multiple case study, with 19 interviews with swine producers and the analysis of 12 contracts. The results show an organizational diversity and its dynamics. The contract incentives and controls are structured to reach economic and efficiency goals.
\end{abstract}

\section{KEY WORDS}

contracts, coordenation, agribusiness, swine production

\section{JEL ClASSIFICATION}

L2; L22

\footnotetext{
* Pesquisador da Embrapa Suínos e Aves e Doutor pelo PPG-Agronegócios da UFRGS. E-mail: mmiele@cnpsa.embrapa.br. End. para contato: BR 153, Km I 10, Caixa Postal 2I, Vila Tamanduá - CEP: 89.700-000. Concórdia - SC.

** Professor Adjunto do Departamento de Economia da FCE/UFRGS e bolsista PQ do CNPq. E-mail: waquil@ufrgs. br. End. para contato: Av. João Pessoa, 3I - CEP: 90.040-000. Porto Alegre - RS.

(Recebido em setembro de 2006. Aceito para publicação em abril de 2007).
} 


\section{INTRODUÇÃO E OBJETIVOS}

A cadeia produtiva de carne suína no Brasil apresenta um dos melhores desempenhos econômicos no cenário internacional, aumentando paulatinamente sua participação de mercado, apesar das barreiras técnicas ao comércio internacional e do acirramento da concorrência. No plano interno, em que pesem o baixo crescimento do mercado consumidor de carne suína e problemas estruturais, observa-se a consolidação de grupos agroindustriais com presença internacional, o fortalecimento de um setor pecuário tecnificado e competitivo, o desenvolvimento econômico das regióes produtoras, bem como a geração de emprego e renda entre os trabalhadores urbanos e aqueles suinocultores que não foram excluídos da atividade. As bases desse desempenho são as estratégias empresariais e os avanços tecnológicos e organizacionais incorporados ao longo das duas últimas décadas. Na produção primária vêm ocorrendo mudanças estruturais com aumento de escala, especialização e tecnificação, tendências relacionadas à crescente integração com a estrutura industrial de abate e processamento. Entre as principais empresas e cooperativas agroindustriais que abatem suínos e processam sua carne no Brasil predomina o foco na marca e nos produtos processados para o mercado interno, enquanto para as exportações a atenção volta-se para o custo e o respeito às questões de segurança alimentar (sobretudo sanitárias e de resíduos nos alimentos).

Essas estratégias dominantes baseiam-se na garantia de fornecimento de matéria-prima nas quantidades e qualidade desejadas, bem como na busca de eficiência logística. Isso tem sido alcançado em grande parte através da coordenação da cadeia produtiva por meio dos contratos e de programas de fomento pecuário. Estes instrumentos estabelecem compromissos entre as partes, viabilizam maior padronização e estabilidade da matéria-prima e permitem a transferência de riscos e margens entre os diversos segmentos. Esse modelo organizacional é conhecido no setor como integração, no qual o suinocultor se insere na cadeia produtiva vinculado a uma agroindústria de abate e processamento que, geralmente, também coordena os elos a montante da produção primária, sobretudo na fabricação de ração. A integração predomina na suinocultura da região Sul do País, mas cresce nas demais regiões acompanhando a expansão geográfica das agroindústrias líderes. Entretanto, há uma multiplicidade de formas organizacionais coexistindo, com um expressivo número de suinocultores não integrados, denominados no setor de independentes.

O problema de pesquisa aqui focalizado se resume em duas perguntas: qual a importância dos contratos na coordenação da transação entre suinocultores e agroindústrias na cadeia produtiva da carne suína em Santa Catarina? Qual a estrutura de incentivos e controles desses contratos? Assim, a presente pesquisa teve por objetivo caracterizar a transação entre os suinocultores e as empresas e cooperativas agroindustriais que 
abatem e processam suínos em Santa Catarina ( $\mathrm{T}_{2}$, na Figura 1). Além disso, e tendo em vista que os fornecedores de genética, ração e demais insumos ora pertencem a essas agroindústrias, ora subordinam-se em grande medida às suas especificações, considera-se também aspectos da transação do suinocultor com seus fornecedores ( $\mathrm{T}_{1}$, na Figura 1). O outro objetivo da pesquisa foi caracterizar e descrever a estrutura de incentivos e controles nos contratos de integração utilizados por essas empresas e cooperativas agroindustriais.

FIGURA I - TRANSAÇÕES ENTRE SUINOCULTORES, SEUS FORNECEDORES E A AGROINDÚSTRIA DE ABATE E PROCESSAMENTO

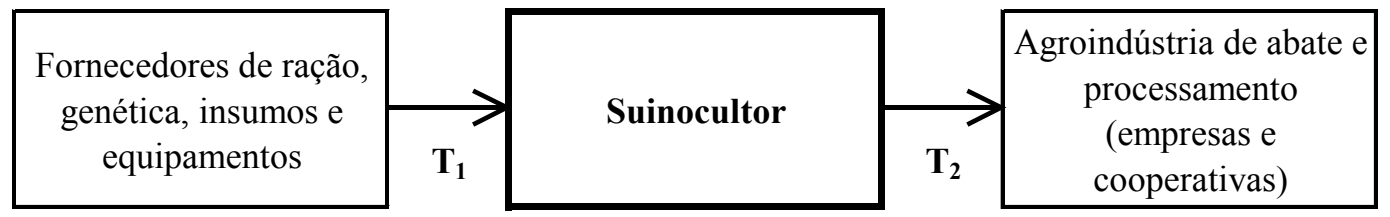

Fonte: adaptado pelos autores a partir de Zylbersztajn (2005).

\section{FUNDAMENTAÇÃO TEÓRICA}

\subsection{A Coordenação das Relações Verticais de Produção no Agronegócio e o Papel dos Contratos}

Há três formas genéricas de organização que respondem de forma efetiva a mudanças no ambiente econômico, institucional e natural, quais sejam: o mercado (sistema de preços), as formas híbridas (contratos e outros arranjos organizacionais) e a hierarquia (integração vertical plena). Essas "estruturas de governança” diferem e podem ser descritas a partir da sua habilidade adaptativa diante de circunstâncias mutantes, bem como a partir dos controles e incentivos que as caracterizam. Portanto, há uma variedade de estruturas organizacionais que podem coordenar a transferência de produtos ao longo de uma cadeia produtiva, ou seja, através das quais as várias funções de um sistema de produção são mantidas em harmonia. Esta capacidade de coordenação está associada à sua estrutura de incentivos para alinhar objetivos entre as partes, ou à sua capacidade de monitoramento e controle para reduzir problemas de informação assimétrica e comportamento oportunista (Blois, 1972; Williamson, 1979 e 1991; Sporleder, 1992; Barkema, 1993; Joskow, 1995; Farina et al., 1997; Zylbersztajn, 2005).

A literatura econômica que aborda as transações e os contratos ressalta que os agentes econômicos se organizam de forma a resolver problemas de quebra contratual e 
seleção adversa. A quebra contratual ocorre quando os termos de uma transação são total ou parcialmente desrespeitados, em função de comportamento oportunista (ação oculta) ou pela ocorrência de eventos inesperados (incerteza do ambiente). Por sua vez, a seleção adversa ocorre quando não há informação adequada que permita aos agentes distinguir questões qualitativas do produto ou do seu produtor (informação oculta). Nesse sentido, há três tipos de termos contratuais importantes. Em primeiro lugar, aqueles voltados à definição das atribuições, obrigações e prerrogativas dos agentes envolvidos em uma transação (alocação de direitos de decisão). Em segundo lugar, aqueles que definem regras de remuneração (incentivos) baseadas em um critério de desempenho facilmente observável, a fim de alinhar objetivos entre as partes. Em terceiro lugar, como contrapartida aos direitos de decisão e às regras de incentivo, há os termos que definem formas de acesso à informação como o monitoramento e a supervisão a fim de reduzir a informação assimétrica (controles). Alguns contratos conseguem implementar a divisão de tarefas e incentivos sobre critérios observáveis e verificáveis, entretanto a informação não é completa e há custos para coletá-la. Por isso, enquanto alguns contratos focam a observação no resultado em função da facilidade em obter informações a partir do produto final, outros contratos focam a observação no processo ou no comportamento, a fim de obter garantias de que um certo resultado dificilmente mensurável será alcançado. Além disso, o monitoramento é impreciso, havendo dificuldades em separar o desempenho obtido em função das ações do agente (esforço) daquele obtido em função de questôes exógenas e incertas (sorte ou azar). Isso em parte é resolvido quando há agentes múltiplos envolvidos na transação ou quando há transações repetidas. Em ambos os casos, ocorre uma redução na incerteza por falta de informação visto que é possível estimar o desempenho de um dado agente a partir dos demais (seus pares) ou do seu histórico. Entretanto, boa parte desses problemas permanece sem solução, levando ao surgimento de termos de exclusividade e remuneração fixa nos contratos (Alchian; Demsetz, 1972; Klein et al., 1978; Eisendhart, 1989; Arrow, 1991; Pratt; Zeckhauser, 1991; Klein, 1992).

O estudo do agronegócio pela ótica sistêmica ocorre a partir de inúmeras escolas e filiações teóricas, das quais as duas mais difundidas são a escola francesa das filières e a Commodity System Approach (CSA). Ambas propõem a análise das atividades agroindustriais considerando os sucessivos estágios de produção e suas interações, bem como o ambiente institucional e macroeconômico. Essa literatura enfatiza a mudança da coordenação através do sistema de preços para a utilização de mecanismos de controle administrativo entre empresas e dentro delas, como a integração vertical (hierarquia) e a crescente contratualização. Essa mudança faz parte de um processo maior de industrialização da agricultura, que evoluiu para a produção diferenciada e para o maior controle dos fluxos de produtos e da informação, características dos setores industriais. É importante salientar que ao longo deste processo ocorre o aumento da ingerência de uma das partes da transação em relação à outra. 
Na maioria dos casos, a agroindústria processadora é a contratante, com um papel proativo a partir do qual exerce maior ingerência sobre seus fornecedores. ${ }^{1}$ Várias são as mudanças que levam à adaptação coordenada, com destaque para a evolução do mercado consumidor cada vez mais exigente, qualificado e diversificado, o acirramento da concorrência e a necessidade de compartilhamento de riscos e a crescente problemática da poluição e da degradação dos recursos naturais (Golberg, 1968; Labonne, 1985; Mariotti; Cairnaca, 1986; Frank; Henderson, 1992; Barkema, 1993; Menard,1996; Zylbersztajn; Farina, 1998; Zylbersztajn, 2005).

\subsection{Coordenação, Contratos e Programas de Fomento na Suinocultura}

A integração da produção através de contratos ou programas de fomento é a forma mais difundida de coordenação da transação entre suinocultores e agroindústrias de abate e processamento nos principais países produtores de carne suína, inclusive no Brasil, e sua participação e importância vêm crescendo nas duas últimas décadas. Há grande diversidade de instrumentos e formas, que diferem em função do tipo de organização da agroindústria e do estabelecimento suinícola. Diferem, também, em função da estrutura de termos contratuais (formais ou não), ou seja, do seu conteúdo (Barkema; Cook, 1993; Altmann, 1997; Lawrence et al., 1997; Guivant; Miranda, 1999; Martinez, 1999; Lawrence et al., 2001; Vukina, 2003; Martinez; Zering, 2004; Weydmann, 2004; Miele, 2006).

O primeiro tipo de cláusula diz respeito à divisão de responsabilidades técnicas, gerenciais e financeiras quanto ao fornecimento de mão-de-obra, insumos e serviços, bem como quanto à propriedade dos ativos envolvidos. Neste grupo também podem ser incluídas as cláusulas que definem os volumes mínimos a serem produzidos e garantias de exclusividade. Esses termos contratuais não apenas alocam direitos de propriedade, mas também direitos de decisão. Outro conjunto de termos contratuais envolve os métodos de cálculo da remuneração do suinocultor e abordam a questão dos incentivos e da repartição do risco. A remuneração é feita geralmente a partir de uma base de cálculo (medida de volume em cabeças ou peso de carcaça), multiplicada por um preço de referência no mercado e acrescida de um bônus (incentivo). Este bônus está relacionado ao desempenho do suinocultor, que é mensurado em função de variáveis facilmente observáveis e verificáveis pela agroindústria, como os critérios de eficiência produtiva, de uniformidade e de adequação a boas práticas de produção. Há também provisões específicas para limitar ou transferir o risco como garantias de pagamento mínimo, teto para preços e a incorporação de indexadores em função do preço da ração. Um terceiro conjunto de termos contratuais aloca direitos de decisão para a agroindústria, como as especificações técnicas (biosegurança, genética,

1 Os produtores rurais também elaboram contratos a fim de complementar sua produção. 
alimentação, instalações, medicamentos, transporte etc.), a definição de padrões e critérios de qualidade (faixas de peso, idade e sanidade), bem como de condições de exclusividade quanto ao fornecimento de insumos e de genética que garantem maior qualidade e uniformidade. Além disso, há um conjunto de cláusulas e termos contratuais que envolvem formas de monitoramento e de acesso à informação a partir do papel da assistência técnica, de programas de tipificação de carcaça baseados em novas tecnologias da informação, de exames laboratoriais e de outros instrumentos como os registros mantidos pelos suinocultores (Lawrence et al., 1997; Martinez, 1999; Lawrence et al., 2001; Vukina, 2003; Martinez; Zering, 2004; Miele, 2006).

Esses elementos em conjunto apontam para a existência de dois tipos básicos de contratos na relação entre suinocultores e agroindústrias, quais sejam, os contratos de compra e venda (marketing contracts) e os contratos de produção ou de parceria (production contracts). Os contratos de compra e venda garantem o escoamento da produção e definem a fórmula de cálculo da remuneração. Entretanto, limitam-se a essas dimensões, visto que as decisões de produção permanecem com o suinocultor, que detém a propriedade dos ativos. Neste tipo de contrato o risco envolvido na produção é do suinocultor, enquanto o risco de mercado (variaçóes nos preços dos insumos e do suíno) é repartido com a agroindústria. Por sua vez, os contratos de produção ou de parceria, além de determinar os mecanismos de remuneração, especificam em detalhes os insumos a utilizar e parâmetros mínimos de qualidade. Na suinocultura integrada são os contratos mais comuns. Em um típico contrato de integração a agroindústria contratante fornece ração, leitões, serviços veterinários, assistência gerencial e serviços de comercialização e genética (o que representa mais ou menos $80 \%$ dos custos de produção). Por outro lado, o produtor contratado fornece instalações, mão-de-obra, água, equipamentos e gestão dos dejetos (Barkema; Cook, 1993; Vukina, 2003; Martinez; Zering, 2004).

\section{METODOLOGLA DA PESQUISA}

O trabalho proposto utiliza uma técnica de investigação qualitativa, de estudo de caso, considerada mais adequada aos fenômenos organizacionais porque compreende a sua complexidade, os limites pouco claros entre o fenômeno e o contexto, e lida com o fato de haver mais variáveis de interesse do que observações (Yin, 2001). Não há amostragem em um estudo de caso visto que o objetivo é fazer uma generalização analítica e não enumerar freqüências (generalização estatística). Neste estudo de caso organizacional, a unidade principal de análise é a transação entre suinocultores e agroindústrias, e as subunidades são membros dessas organizações. Baseou-se em um protocolo contendo os instrumentos de coleta de dados e os procedimentos e 
regras gerais que devem ser seguidos ao utilizá-los, aumentando a confiabilidade da pesquisa. A coleta de dados baseou-se em três princípios: a busca por evidências provenientes de duas ou mais fontes (entrevistas, documentos e dados secundários); a organização de um banco de dados para o estudo de caso (reunião formal das distintas evidências); e a busca por um encadeamento de evidências para fazer ligações entre as questões de pesquisa, os dados coletados e as conclusões (Yin, 2001).

O procedimento mais importante foi o acesso aos entrevistados, para tanto, contou-se com o apoio da Associação Catarinense de Criadores de Suínos (ACCS) ${ }^{2}$, que realizou contatos telefônicos prévios. As entrevistas e a coleta de documentos e dados secundários ocorreram nos meses de janeiro e fevereiro de 2006, no Oeste de Santa Catarina. Esta tarefa foi conduzida a partir de três instrumentos de coleta de dados: o roteiro estruturado de entrevistas, o roteiro para tabulação das cláusulas contratuais e o roteiro para tabulação de dados quantitativos. Foram entrevistados 19 suinocultores abrangendo os sistemas de produção em ciclo completo (CC), em unidades produtoras de leitão (UPL) e em unidades de terminação (UT), assim como as cinco principais agroindústrias processadoras de carne suína em Santa Catarina (Sadia, Perdigão, Aurora, Seara e Pamplona) e a atuação dos independentes. Além disso, foram analisados 12 contratos, seus adendos e outros documentos relacionados, abrangendo a diversidade de contratos em função do período (de 1998 a 2005), das agroindústrias que atuam desta forma (Aurora, Perdigão, Sadia e Seara) e dos sistemas de produção existentes (CC, UPL e UT). Todos os contratos analisados estão em vigência. Apesar de não ser estatisticamente representativa, a amostra de suinocultores e de contratos contempla a diversidade da cadeia produtiva (Tabelas 1 e 2).

\section{TRANSAÇÃO ENTRE SUINOCULTORES E AGROINDÚSTRIAS}

Com exceção dos suinocultores independentes, todos os entrevistados são integrados ou fornecedores das cinco principais agroindústrias nesse segmento no Brasil (Tabelas l e 2), com $75 \%$ das exportações e $56 \%$ dos abates sob inspeção federal, e quatro delas encontram-se entre as maiores empresas de carne suína no mundo. Esse grupo pode ser caracterizado como um oligopólio competitivo, no qual predomina a busca por ganhos de escala, a promoção da marca, a coordenação da cadeia produtiva, a inovação em produtos e processos e crescentes controles de qualidade. Do ponto de vista da gama de produtos, também atuam no segmento de carne de frango e, mais recentemente, de carne bovina e de alimentos em geral, com uma estratégia de produtos processados para o mercado interno e de carne in natura para as exportações.

2 Os autores agradecem o apoio do Sr. Losivanio Luiz de Lorenzi, Vice-Presidente da ACCS. 
Do ponto de vista da extensão vertical das estratégias, predomina um padrão de investimentos que se estende da distribuição à produção de insumos, com os estabelecimentos suinícolas inseridos geralmente através de programas de fomento pecuário e de contratos (Rabobank, 2001; Santini; Souza Filho, 2004, Weydmann, 2004; Miele, 2006).

TABELA 1 - PARTICIPAÇÃO DAS AGROINDÚSTRIAS ANALISADAS NA CADEIA PRODUTIVA DA CARNE SUÍNA EM SANTA CATARINA E NO BR ASIL, EM 2005

\begin{tabular}{|c|c|c|c|c|c|c|c|}
\hline \multirow{2}{*}{ Agroindústria } & \multicolumn{3}{|c|}{ Participação em Santa Catarina } & \multirow{2}{*}{$\begin{array}{c}\text { Posição no } \\
\text { Brasil }\end{array}$} & \multirow[t]{2}{*}{ Diversificação* } & \multicolumn{2}{|c|}{ Unidades de Abate de Suínos } \\
\hline & Estabelec. & Matrizes & Abates & & & Localização & N. ${ }^{\circ}$ \\
\hline Sadia & $14 \%$ & $17 \%$ & $13 \%$ & $1^{a}$ & $A, B, S$ & $\mathrm{SC}, \mathrm{PR}, \mathrm{RS}, \mathrm{MG}$ & 4 \\
\hline Perdigão & $8 \%$ & $17 \%$ & $22 \%$ & $2^{a}$ & $A, B, S$ & $\mathrm{SC}, \mathrm{RS}, \mathrm{PR}, \mathrm{GO}$ & 5 \\
\hline Aurora & $57 \%$ & $36 \%$ & $26 \%$ & $3^{a}$ & $A, S$ & SC, RS, MS & 7 \\
\hline Seara & $12 \%$ & $17 \%$ & $15 \%$ & $4^{a}$ & $A, B, S$ & SC, MS & 2 \\
\hline Pamplona & $9 \%$ & $12 \%$ & $16 \%$ & $5^{a}$ & $B, S$ & SC & 2 \\
\hline Outros & $0,4 \%$ & $1 \%$ & $8 \%$ & - & - & - & - \\
\hline
\end{tabular}

Fontes: Sindicato das Indústrias de Carnes e Derivados no Estado de Santa Catarina (2005) e Associação Brasileira da Indústria Produtora e Exportadora de Carne Suína (2005).

* Tipos de carnes processadas pela empresa, em que $\mathrm{A}=$ aves, $\mathrm{B}=$ bovinos e $\mathrm{S}=$ suínos.

TABELA 2 - NÚMERO DE ESTABELECIMENTOS ENTREVISTADOS, POR SISTEMA DE PRODUÇÃO E TIPO DE VÍNCULO

\begin{tabular}{|c|c|c|c|c|c|c|c|}
\hline Tipo de vínculo & & $\mathrm{CC}$ & UPL & UT & \multicolumn{3}{|c|}{ Total por vínculo } \\
\hline \multirow{4}{*}{$\begin{array}{l}\text { Empresas } \\
\text { agroindustriais }\end{array}$} & Pamplona & 2 & 1 & 1 & 4 & $21 \%$ & \multirow{4}{*}{$63 \%$} \\
\hline & Perdigão & 0 & 1 & 1 & 2 & $11 \%$ & \\
\hline & Sadia & 1 & 1 & 2 & 4 & $21 \%$ & \\
\hline & Seara & 0 & 1 & 1 & 2 & $11 \%$ & \\
\hline Cooperativa Aurora & & 2 & 1 & 1 & 4 & & \\
\hline Independentes & & 1 & 1 & $1^{*}$ & 3 & & \\
\hline \multirow{2}{*}{ Total por sistema } & & 6 & 6 & 7 & 19 & & \\
\hline & & $32 \%$ & $32 \%$ & $37 \%$ & $100 \%$ & & \\
\hline
\end{tabular}

* Não existindo UTs independentes, optou-se por entrevistar um comerciante de suínos denominado mini-integrador.

Fonte: elaborada pelos autores.

Os estabelecimentos em CC entrevistados têm como característica principal uma escala grande ou média ${ }^{3}$, especialização na suinocultura, mas com fontes de renda com o transporte de animais e a produção de milho para a ração. Os estabelecimentos em

3 A definição da escala de produção como grande, média ou pequena ocorreu em função do padrão existente na região. 
UPL têm como característica principal uma escala de produção média e em alguns casos grande, e altamente especializados na suinocultura, e a maioria atua ou está em transição para atuar somente com suínos. Os estabelecimentos em UT apresentam maior diversidade na escala de produção, com grandes, médios e pequenos. Todos são diversificados, visto que nenhum percebe mais do que $50 \%$ da renda através da suinocultura, que é complementada pela atividade leiteira e rendas urbanas (emprego do cônjuge e transporte). A maioria dos entrevistados retirou-se da produção de aves e o plantio de grãos é marginal, associado à fabricação de ração.

A determinação do espectro de formas organizacionais na transação entre suinocultores e empresas e cooperativas agroindustriais de Santa Catarina contempla a terminologia utilizada pelos agentes da cadeia produtiva (practitioners), assim como as estruturas de governança propostas pela teoria.

\subsection{Suinocultura Integrada Através de Contratos}

Os contratos são a forma predominante de organização da produção em Santa Catarina, envolvendo mais da metade dos abates, pouco menos da metade das matrizes e quase dois terços dos estabelecimentos suinícolas (Tabelas 3, 4 e 5). Existem três tipos básicos: os contratos de compra e venda (geralmente com UPLs mas não exclusivamente), os contratos de parceria com UTs e os de comodato com UPLs. Os estabelecimentos em CC geralmente não aderem a contratos. Também existem contratos dos produtores e das agroindústrias com empresas especializadas para o desenvolvimento de programas de melhoramento genético ou de nutrição, ou empresas certificadoras.

Do ponto de vista das relações a montante do estabelecimento suinícola $\left(\mathrm{T}_{1}\right)$, esses três tipos de contratos apresentam exigências quanto à origem da genética e da ração, especificações técnicas de manejo e retirada de medicamentos e o provimento de assistência técnica e transporte. Do ponto de vista das relações a jusante do estabelecimento suinícola $\left(\mathrm{T}_{2}\right)$, os três tipos de contratos apresentam garantias formais de compra e venda, especificações de volume e prazos, exigência de exclusividade, definição de um preço de referência ${ }^{4}$ e de critérios de remuneração em função do desempenho e uniformidade.

A diferença ocorre em relação à propriedade dos ativos. Nos contratos de compra e venda, o suinocultor é proprietário das instalações, equipamentos e reprodutores, e deve adquirir (à vista ou a prazo) leitões, ração e insumos. Nos contratos de parceria

4 No caso de Santa Catarina geralmente é o preço do suíno vivo estabelecido pelo Sindicato das Indústrias de Carnes e Derivados no Estado de Santa Catarina (Sindicarnes-SC). 
e de comodato, o suinocultor detém apenas as instalaçóes e equipamentos. Cabe à agroindústria arcar com os custos dos leitões (no caso das UTs) ou dos reprodutores (no caso das UPLs), bem como da ração e parte dos insumos. Ao ingressar na integração, o suinocultor passa a ser fiel depositário destas mercadorias. Em todos esses contratos cabem ao suinocultor as despesas com mão-de-obra, energia, água, manutenção e manejo ou tratamento dos dejetos. Também cabe à agroindústria arcar com os custos com assistência técnica, transporte dos animais e, na maioria das vezes, transporte da ração. Em função desta divisão de responsabilidades, percebe-se que nos contratos de parceria e de comodato há transferência de parte dos riscos de variação dos preços (dos grãos e dos insumos) do suinocultor para a agroindústria, enquanto nos contratos de compra e venda estes riscos permanecem junto ao produtor rural. Em todos os casos, o risco ambiental associado à gestão dos dejetos é transferido ao suinocultor.

\subsection{Suinocultura Integrada Através de Programas de Fomento}

Cerca de um terço dos suinocultores catarinenses não aderem a contratos formais, mas estão inseridos na cadeia produtiva através de programas de fomento pecuário de empresas agroindustriais e, sobretudo, das cooperativas. Essa forma de coordenação ocorre entre estabelecimentos em CC, em UPL e UT (Tabelas 3, 4 e 5) e, apesar de não existir um instrumento jurídico formal para amparar a transação, pode-se afirmar que fazem parte da suinocultura integrada, tendo em vista que nesse tipo de vínculo, denominado pela teoria de acordo tácito, há diversas semelhanças com a transação anteriormente descrita.

Na relação a montante do estabelecimento suinícola $\left(\mathrm{T}_{1}\right)$, observa-se a prática de venda à vista ou a prazo de reprodutores e ração entre as UPLs, ou o fornecimento de leitões e ração entre as UTs, a existência de algumas especificações técnicas como a retirada de medicamentos antes do abate e o papel da assistência técnica como elo central de relacionamento. $\mathrm{Na}$ transação a jusante $\left(\mathrm{T}_{2}\right)$, predominam as garantias mútuas de compra e venda, comprometimentos de exclusividade, a definição de um preço de referência e formas de remuneração baseadas em critérios previamente acordados e, por fim, o transporte dos animais (que às vezes é assumido pelo próprio suinocultor).

Note-se que apesar das semelhanças, há um menor grau de comprometimento formal entre as partes, geralmente sujeito ao desenvolvimento de relações de confiança e conhecimento mútuo, sobretudo no sistema cooperativo. Além disso, o suinocultor tem maior liberdade para selecionar fornecedores, a partir de uma análise de custobenefício sem exclusividade. Nesses casos o suinocultor é responsável pelas decisões 
técnicas (principalmente em genética, nutrição e medicamentos), enquanto na relação amparada por contratos a margem de manobra é menor.

\subsection{Suinocultura Independente}

A coordenação externa via mercado spot, na qual os preços servem como principal parâmetro na tomada de decisão, caracteriza o que no setor chama-se de suinocultura independente. Nas relações a montante do estabelecimento suinícola $\left(T_{1}\right)$, a seleção de fornecedores se dá a partir de uma análise de custo-benefício sem exclusividade, mas pode-se encontrar contratos com empresas de genética ou nutrição. Nas relações a jusante $\left(\mathrm{T}_{2}\right)$ o suinocultor faz tomadas de preço junto a compradores diversos como comerciantes, agroindústrias, pequenos abatedores locais, e suinocultores de outras regiôes. A maioria desses estabelecimentos opera em CC ou UPL, não existindo UTs independentes, mas sim comerciantes que subcontratam ou estabelecem acordos tácitos com terminadores de menor escala, geralmente excluídos da integração. Esse fenômeno é denominado no setor como mini-integração.

Na suinocultura independente, cabe ao suinocultor a responsabilidade pelas decisões técnicas assim como os investimentos não apenas em instalações, equipamentos e reprodutores, mas no capital de giro necessário à aquisição de ração, leitões (quando for o caso), demais insumos e despesas. Este tipo de vínculo representa maior risco para o suinocultor, sobretudo pela falta de garantias de escoamento da produção. Por outro lado, permite a obtenção de maior remuneração, principalmente em períodos de mercado aquecido.

Em Santa Catarina a suinocultura independente tem menor expressão quando comparada à integração (Tabelas 3, 4 e 5). No Oeste do Estado, contempla pequenos estabelecimentos em UPLs e em UTs quase sempre vinculados aos mini-integradores ou alguns poucos estabelecimentos de maior escala em CC ou UPL. No sul do Estado essa forma de organização predomina, com suinocultores de maior porte, geralmente em CC. Por fim, merece destaque a existência de alianças estratégicas entre suinocultores independentes, através de pequenas cooperativas de autogestão e experiências associativas para a aquisição conjunta de insumos e a formação de lotes de venda, com o intuito de reduzir os custos de produção ou comercialização e obter maior poder de barganha. 
TABELA 3 - PARTICIPAÇÃO DOS CONTRATOS, DOS PROGRAMAS DE FOMENTO E DOS INDEPENDENTES ENTRE OS ESTABELECIMENTOS SUINÍCOLAS DE SANTA CATARINA, EM 2001 E 2005

\begin{tabular}{|c|c|c|c|c|c|c|}
\hline \multirow[b]{2}{*}{ Tipo de vínculo } & \multirow{2}{*}{$\begin{array}{l}\text { Sistema de } \\
\text { produção }\end{array}$} & \multicolumn{2}{|c|}{ Dezembro de 2001} & \multicolumn{2}{|c|}{ Outubro de 2005} & \multirow{2}{*}{$\begin{array}{c}\text { Variação no } \\
\text { período }\end{array}$} \\
\hline & & $\begin{array}{c}\mathrm{N} .^{\circ} \text { de } \\
\text { estabelec. }\end{array}$ & Participação & $\begin{array}{c}\mathrm{N} .^{\circ} \mathrm{de} \\
\text { estabelec. }\end{array}$ & Participação & \\
\hline \multirow{4}{*}{ Independente* } & $\mathrm{CC}$ & 231 & $2,0 \%$ & 123 & $1,3 \%$ & $-47 \%$ \\
\hline & UPL & 38 & $0,3 \%$ & 27 & $0,3 \%$ & $-29 \%$ \\
\hline & UT & 13 & $0,1 \%$ & 5 & $0,1 \%$ & $-62 \%$ \\
\hline & Total & 282 & $2,5 \%$ & 155 & $1,7 \%$ & $-45 \%$ \\
\hline \multirow{5}{*}{ Programa de fomento } & CC & 4.352 & $38,2 \%$ & 1.578 & $17,3 \%$ & $-64 \%$ \\
\hline & GR & 4 & $0,04 \%$ & 4 & $0,04 \%$ & $0 \%$ \\
\hline & UPL & 1.381 & $12,1 \%$ & 1.448 & $15,9 \%$ & $5 \%$ \\
\hline & UT & 260 & $2,3 \%$ & 398 & $4,4 \%$ & $53 \%$ \\
\hline & Total & 5.997 & $52,7 \%$ & 3.428 & $37,6 \%$ & $-43 \%$ \\
\hline \multirow{3}{*}{ Contrato de compra e venda } & $\mathrm{UPL}^{* *}$ & 898 & $7,9 \%$ & 781 & $8,6 \%$ & $-13 \%$ \\
\hline & UT & 1.541 & $13,5 \%$ & 1.127 & $12,4 \%$ & $-27 \%$ \\
\hline & Total & 2.439 & $21,4 \%$ & 1.908 & $20,9 \%$ & $-22 \%$ \\
\hline Contrato de parceria & UT & 2.640 & $23,2 \%$ & 3.621 & $39,7 \%$ & $37 \%$ \\
\hline Integração vertical plena & GR & 29 & $0,3 \%$ & 12 & $0,1 \%$ & $-60 \%$ \\
\hline \multicolumn{2}{|l|}{ Total Geral } & 11.387 & $100,0 \%$ & 9.124 & $100 \%$ & $-20 \%$ \\
\hline
\end{tabular}

Fonte: estimativas dos autores com base nas entrevistas e nos relatórios do Sindicato das Indústrias de Carnes e Derivados no Estado de Santa Catarina (2005).

* valores subestimados porque desconsideram os estabelecimentos vinculados aos mini-integradores.

** não foi possível desagregar os estabelecimentos com contrato de comodato.

TABELA 4 - PARTICIPAÇÃO DOS CONTRATOS, DOS PROGRAMAS DE FOMENTO E DOS INDEPENDENTES NOS ABATES DE SANTA CATARINA, EM 2001 E 2005

\begin{tabular}{|c|c|c|c|c|c|c|}
\hline \multirow[b]{2}{*}{ Tipo de vínculo } & \multirow{2}{*}{$\begin{array}{l}\text { Sistema de } \\
\text { produção }\end{array}$} & \multicolumn{2}{|c|}{ Dezembro de 2001} & \multicolumn{2}{|c|}{ Outubro de 2005} & \multirow{2}{*}{$\begin{array}{c}\text { Variação no } \\
\text { período }\end{array}$} \\
\hline & & $\begin{array}{l}\text { Cabeças } \\
\text { abatidas }\end{array}$ & Participação & $\begin{array}{l}\text { Cabeças } \\
\text { abatidas }\end{array}$ & Participação & \\
\hline \multirow{4}{*}{ Independente* } & $\mathrm{CC}$ & 17.837 & $3,6 \%$ & 15.141 & $2,5 \%$ & $-15 \%$ \\
\hline & UT & 2.618 & $0,5 \%$ & 3.163 & $0,5 \%$ & $20 \%$ \\
\hline & Outros* & 55.419 & $11 \%$ & 54.804 & $9 \%$ & $-1 \%$ \\
\hline & Total & 75.874 & $15 \%$ & 73.108 & $12 \%$ & $-4 \%$ \\
\hline \multirow{3}{*}{ Programa de fomento } & $\mathrm{CC}$ & 129.921 & $26 \%$ & 90.496 & $15 \%$ & $-30 \%$ \\
\hline & UT & 38.836 & $8 \%$ & 101.845 & $17 \%$ & $162 \%$ \\
\hline & Total & 168.797 & $34 \%$ & 192.341 & $32 \%$ & $14 \%$ \\
\hline Contrato de compra e venda & UT & 65.114 & $13 \%$ & 68.610 & $11 \%$ & $5 \%$ \\
\hline Contrato de parceria & UT & 182.792 & $37 \%$ & 266.727 & $44 \%$ & $46 \%$ \\
\hline Total Geral & & 492.577 & $100 \%$ & 600.786 & $100 \%$ & $22 \%$ \\
\hline
\end{tabular}

Fonte: estimativas dos autores com base nas entrevistas e nos relatórios do Sindicato das Indústrias de Carnes e Derivados no Estado de Santa Catarina (2005).

* sistema de produção não disponível, provavelmente suinocultores vinculados a mini-integradores. 
TABELA 5 - PARTICIPACÃO DOS CONTRATOS, DOS PROGRAMAS DE FOMENTO E DOS INDEPENDENTES NO ALOJAMENTO DE MATRIZES EM SANTA CATARINA, EM 2001 E 2005

\begin{tabular}{|c|c|c|c|c|c|c|}
\hline \multirow[b]{2}{*}{ Tipo de vínculo } & \multirow{2}{*}{$\begin{array}{l}\text { Sistema de } \\
\text { produção }\end{array}$} & \multicolumn{2}{|c|}{ Dezembro de 2001} & \multicolumn{2}{|c|}{ Outubro de 2005} & \multirow{2}{*}{$\begin{array}{c}\text { Variação no } \\
\text { período }\end{array}$} \\
\hline & & $\begin{array}{l}N{ }^{\circ} \text { de } \\
\text { matrizes }\end{array}$ & Participação & $\begin{array}{l}\mathrm{N} .{ }^{\circ} \text { de } \\
\text { matrizes }\end{array}$ & Participação & \\
\hline \multirow{4}{*}{ Independente* } & $\mathrm{CC}$ & 10.911 & $3 \%$ & 10.019 & $3 \%$ & $-8 \%$ \\
\hline & UPL & 1.806 & $0,6 \%$ & 1.772 & $0,6 \%$ & $-2 \%$ \\
\hline & Outros ${ }^{* *}$ & 11.075 & $4 \%$ & 0 & $0 \%$ & $-100 \%$ \\
\hline & Total & 23.792 & $8 \%$ & 11.791 & $4 \%$ & $-50 \%$ \\
\hline \multirow{3}{*}{ Programa de fomento } & $\mathrm{CC}$ & 111.219 & $35 \%$ & 50.484 & $16 \%$ & $-55 \%$ \\
\hline & UPL & 74.605 & $24 \%$ & 107.616 & $35 \%$ & $44 \%$ \\
\hline & Total & 185.824 & $59 \%$ & 158.100 & $51 \%$ & $-15 \%$ \\
\hline Contrato de compra e venda & UPL & 105.348 & $33 \%$ & 140.637 & $45 \%$ & $33 \%$ \\
\hline Contrato de comodato*** & UPL & n.d. & n.d. & n.d. & n.d. & n.d. \\
\hline Total Geral & & 314.964 & $100 \%$ & 310.528 & $100 \%$ & $-1 \%$ \\
\hline
\end{tabular}

Fonte: estimativas dos autores com base nas entrevistas e nos relatórios do Sindicato das Indústrias de Carnes e Derivados no Estado de Santa Catarina (2005).

* valores subestimados porque desconsideram os estabelecimentos vinculados aos mini-integradores.

** sistema de produção não disponível, denominados pelas agroindústrias de terceiros.

*** dados não disponíveis, contabilizados nas UPLs com contrato de compra e venda.

\subsection{A Integração Vertical Plena}

Por fim, deve-se ressaltar experiências de integração vertical plena ou coordenação interna (hierarquia), na qual um estabelecimento suinícola desenvolve atividades produtivas típicas das agroindústrias ou dos fornecedores de insumos. Na relação a montante $\left(\mathrm{T}_{1}\right)$ entre os estabelecimentos em CC ou UPL, é comum a produção própria de ração e, com menor freqüência, de reprodutores (fêmeas, machos e sêmen). Na relação a jusante $\left(T_{2}\right)$, ocorre a integração vertical plena com investimentos do suinocultor em atividades de agroindustrialização e comercialização de produtos derivados da suinocultura, como os embutidos ou o composto orgânico, práticas geralmente associadas às chamadas agroindústrias familiares. A integração vertical plena também ocorre entre as agroindústrias processadoras de carne suína em Santa Catarina, que possuem fábricas de ração e programas próprios de melhoramento genético e granjas de reprodutores (GR). A produção de leitões e suínos para o abate em estabelecimentos próprios das agroindústrias não é muito freqüente, ocorrendo apenas entre pequenos abatedores. 


\subsection{Do Independente à Integração Vertical Plena: Formas Organizacionais Existentes na Transação Entre Suinocultores e Agroinduistrias}

Existem fatores que tornam tênues os limites entre essas categorias. De fato, a existência de um sistema cooperativo ou de um programa de fomento baseado em assistência técnica estabelece condições para o desenvolvimento de relações de confiança, conhecimento mútuo e aprendizado. O mesmo pode ocorrer através da recorrência de sucessivas e bem-sucedidas transações. Por isso as práticas de relacionamento das agroindústrias são importantes. Estes são elementos que viabilizam uma melhor coordenação da transação entre suinocultor e agroindústria, apesar de nem sempre haver um contrato formal que os ampare. O papel da assistência técnica é fundamental (transferência de tecnologia, relacionamento e monitoramento), mas também pode ser pautado por problemas pessoais, culturais e outros determinantes extramercado que podem influenciar até na remuneração.

Por outro lado, fatores conjunturais podem levar ao não cumprimento de cláusulas contratuais como o volume dos lotes, os prazos de engorda e repovoamento e, em alguns casos, o sobrealojamento de animais. Além desse relaxamento, há um conjunto de termos (preço de referência, salvaguardas, prazo contratual, renovação e rescisão) que conferem características de mercado à transação sob contrato, visto que há um contínuo processo de relacionamento, negociação e recontratação. Portanto, há um certo grau de indeterminação nesse espectro de formas organizacionais, e os elementos acima apontam para práticas e vicissitudes que reduzem a rigidez dos contratos ou estabilizam a flexibilidade dos acordos tácitos e do mercado. Essa indeterminação fica ainda mais evidente quando se analisa a terminologia utilizada pelos agentes da cadeia produtiva, quais sejam: suinocultura de subsistência, suinocultura industrial independente e suinocultura industrial integrada (Figura 2).

Entende-se por suinocultura industrial o conjunto de produtores tecnificados, ou seja, que incorporam os avanços tecnológicos em genética, nutrição, sanidade e demais aspectos produtivos. Neste grupo encontram-se suinocultores integrados e independentes. O que os agentes da cadeia produtiva chamam de integração abrange um vasto leque de opções, das transações formalizadas por contratos, características desse grupo, até as transações sem contrato mas amparadas no cooperativismo e em programas de fomento pecuário. Assim, do ponto de vista teórico, a suinocultura industrial integrada ocorre não apenas através de contratos, mas também através de acordos tácitos. 
FIGURA 2 - RELAÇÃO ENTRE A TERMINOLOGIA UTILIZADA PELOS AGENTES DA CADEIA PRODUTIVA E A TERMINOLOGIA TEÓRICA PARA AS FORMAS ORGANIZACIONAIS DA TRANSAÇÃO ENTRE SUINOCULTOR E AGROINDÚSTRIA



Fonte: elaborado pelos autores.

Por outro lado, o que os agentes da cadeia produtiva chamam de suinocultura industrial independente também abrange um vasto leque de opçóes, que às vezes se sobrepõe a algumas características da integração, indo das transações no mercado spot (sem contrato nem garantias tácitas) entre agroindústrias, terceiros e mini-integradores, passando pelas transações sem contrato mas amparadas pelo cooperativismo e programas de fomento pecuário, até os suinocultores que têm contratos apenas com fornecedores de genética e nutrição. Do ponto de vista teórico, estes se enquadram nas categorias de coordenação externa e acordos tácitos. Também fazem parte da suinocultura industrial independente os produtores organizados em pequenas cooperativas e outras iniciativas associativas que organizam redes de suprimento ou processam os próprios animais em agroindústrias familiares. Do ponto de vista teórico, estes se enquadram nas categorias de alianças estratégicas e coordenação interna (integração vertical plena). Também se enquadram nesta categoria teórica os investimentos 
das agroindústrias e das cooperativas na produção própria de suínos, geralmente em granjas de reprodutores. Por fim, entende-se por suinocultura de subsistência o conjunto de produtores não tecnificados que não incorporaram os avanços tecnológicos (sobretudo em genética, nutrição e sanidade) e possuem limitações de escala, capital e mão-de-obra, para os quais a produção de suínos é destinada ao autoconsumo ou acessa de forma marginal os principais canais de processamento e distribuição. Neste último caso, são também suinocultores independentes.

\section{ANÁLISE DAS CLÁUSULAS CONTRATUAIS}

A partir da leitura dos documentos, foi estruturado e preenchido um banco de dados das cláusulas contratuais (Tabela 6) que permitiu classificar os temas abordados nos contratos. Além disso, permitiu a comparação entre os documentos em função de mudanças no tempo e entre agroindústrias ou diferentes sistemas de produção.

\subsection{Cláusulas sobre Obrigações das Partes e Volumes de Produção}

Os contratos definem como obrigações das agroindústrias fornecer reprodutores, leitões, ração, medicamentos e outros insumos, prestar serviços de assistência técnica e de transporte. No caso dos contratos de compra e venda (CC, UPL e UT) isso se dá através da venda à vista ou a prazo, enquanto nos de parceria (UT) e em comodato (UPL) isso se dá através da entrega ao suinocultor, que passa a ser fiel depositário dos animais, ração e demais insumos. Neste caso ocorre uma troca na posse, mas não na sua propriedade.

As obrigações do suinocultor são seguir as orientações técnicas da agroindústria, fornecer mão-de-obra familiar ou contratada (inclusive encargos, tributos e responsabilidades decorrentes do seu emprego), prover instalações e equipamentos, água e energia, realizar manutenção e reformas necessárias e manter a trafegabilidade nas vias de acesso às pocilgas. Além disso, deve se responsabilizar pelo tratamento, manuseio, uso, transporte, distribuição e destino dos dejetos, devendo para tanto atender à legislação ambiental (apenas um contrato se omite do tema).

Quase todos os contratos definem volume de produção e capacidade de alojamento. A definição de limites para variações no plantel de reprodutores é utilizada apenas nos contratos de compra e venda em UPL, enquanto os demais condicionam variações nos volumes produzidos ou alojados às necessidades da agroindústria e do suinocultor, 
bem como às exigências do mercado. Há, portanto, uma abertura para que condições extremas de mercado determinem mudanças nos volumes a serem produzidos.

\subsection{Cláusulas sobre Remuneração}

Quanto à remuneração, o contrato em CC é o que menos estabelece provisões neste tema, portanto não será discutido. Os contratos de compra e venda entre as UPLs têm em geral uma apresentação explícita da forma como se dará a remuneração do produtor de leitôes, sobretudo através de tabelas de preços e prazos anexas aos contratos. Definem o peso do leitão entregue como base de cálculo, remetem a um preço de mercado de referência (do suíno vivo ou do leitão), e definem o cálculo ou limites da bonificação.

O principal incentivo (indexador aplicado sobre o preço de referência) é dado em função das faixas de peso dos leitões entregues, indicando que o objetivo perseguido pelas agroindústrias é a padronização dos animais que seguem para engorda e terminação. As faixas de peso mais leves são mais bem remuneradas do que as demais (Figura 3), mas os valores dessas faixas não são uniformes entre as agroindústrias, dependendo das necessidades de cada uma. Note-se que um indexador maior não necessariamente implica maior remuneração, tendo em vista que as agroindústrias podem utilizar diferentes preços de referência ou bonificação.

Além deste incentivo, há um conjunto de especificações técnicas e gerenciais que, quando adotadas pelo suinocultor, dão direito a uma bonificação que acrescenta até $5 \%$ à remuneração final. As especificações técnicas e gerenciais que dão direito a uma bonificação são monitoradas pela assistência técnica ou pela gerência das agroindústrias. Há contratos com check-lists extensos e complexos, enquanto outros são mais simples. Em geral, os seguintes itens podem ser considerados para esta finalidade: adesão a pacotes veterinários, programas de melhoramento genético e de nutrição; biosseguridade; desempenho técnico, escala de produção; gestão e precisão nas informações prestadas e investimentos específicos (como o tipo de carregador de leitões ou silos). 
FIGURA 3 - INDEXADOR A SER APLICADO SOBRE O PREÇO DE REFER $\hat{E N-}$ CIA EM FUNÇÃO DAS FAIXAS DE PESO DOS LEITÕES

Indexador a ser aplicado sobre o preço de referência (1)(2)

\begin{tabular}{|c|c|c|c|c|c|}
\hline $\begin{array}{c}\text { Faixas } \\
\text { de peso } \\
(\mathrm{kg})\end{array}$ & $\begin{array}{c}\text { Agroindústria } 1 \\
\text { Contrato A } \\
\text { (1999) }\end{array}$ & $\begin{array}{c}\text { Agroindústria } 2 \\
\text { Contrato B } \\
\text { (1999) }\end{array}$ & $\begin{array}{c}\text { Agroindústria } 3 \\
\text { Contrato C } \\
\text { (2002) }\end{array}$ & $\begin{array}{c}\text { Agroindústria } 2 \\
\text { Contrato D } \\
\text { (2003) }\end{array}$ & $\begin{array}{c}\text { Agroindústria } 4 \\
\text { Contrato E } \\
(2005)\end{array}$ \\
\hline
\end{tabular}

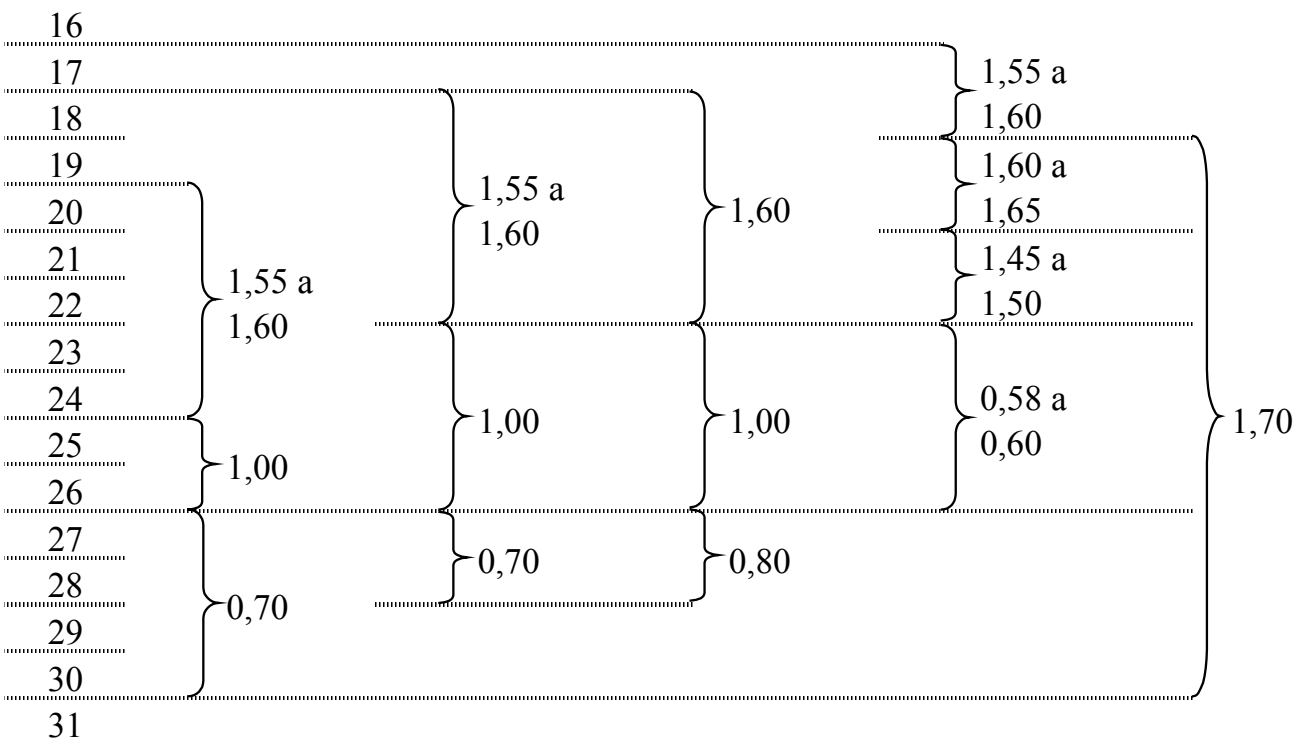

(1) quando há mais de um indexador por faixa de peso, existe a possibilidade de bonificação conforme discutido a seguir.

(2) a mudança de indexador entre as faixas incide apenas sobre o peso adicional, e não sobre todo o peso do leitão.

Fonte: elaborado pelos autores.

Desta forma, a remuneração do suinocultor em UPL segue a fórmula descrita a seguir.

$$
\mathrm{R}=(\mathrm{A} \times \mathrm{B} \times \mathrm{C})+\mathrm{D}
$$

Em que:

$\mathrm{R}=$ remuneração $(\mathrm{R} \$)$

$\mathrm{A}=$ peso individual dos leitões entregues $(\mathrm{kg})$

$\mathrm{B}=$ preço de referência $(\mathrm{R} \$ / \mathrm{kg})$

$\mathrm{C}=$ indexador sobre o preço de referência com base nas faixas de peso dos leitões (índice)

$\mathrm{D}=$ bonificação $(\%)$ 
Nos contratos de parceria com as UTs há dois grupos de documentos, ou seja, os que explicitam a fórmula de remuneração e o preço de referência a ser utilizado e os que se omitem dessas questões, que ficam relegadas ao plano administrativo (não contratual). Nos contratos que explicitam a forma de remuneração, a base de cálculo é o peso da carcaça dos animais entregues para abate ou, em alguns casos, o peso dos suínos vivos. O preço de mercado de referência é o preço da carcaça praticado pela agroindústria no dia do abate. ${ }^{5}$

O principal incentivo (indexador aplicado sobre o preço de referência) é dado em função da conversão alimentar obtida pelo suinocultor no lote entregue para o abate. Isso indica que o objetivo perseguido pelas agroindústrias é reduzir as despesas com alimentação, principal elemento no custo de produção (cerca de 70\%). Na maioria das vezes é considerado o desempenho relativo, ou seja, a conversão alimentar obtida é comparada com a média dos demais lotes entregues nos últimos 30 ou 60 dias, implicando concorrência entre os suinocultores. Apesar de não fazer parte da fórmula de remuneração, a mortalidade dos leitões também deve ser considerada, pois esta interfere no cálculo da conversão alimentar. $\mathrm{O}$ mesmo se pode dizer quanto ao rendimento do animal vivo em volume de carcaça. No entanto, já que esta conversão depende essencialmente da genética empregada, há pouco a ser feito por parte do produtor. Há também contratos que definem um piso para a remuneração do suinocultor, de 2,5\% sobre o valor das carcaças dos animais entregues ao abate. Poucos estabelecem prazos de pagamento.

Além deste incentivo, há um conjunto de especificações técnicas e gerenciais que, quando adotadas pelo suinocultor, dão direito a uma bonificação que acrescenta até $20 \%$ à remuneração final. A incidência desta bonificação não ocorre em todas as agroindústrias, e se dá através de um percentual a ser acrescido na remuneração final. Há contratos com check-lists anexos que consideram os seguintes itens: ambiência, desempenho técnico, investimentos específicos e manejo do rebanho. Desta forma, a remuneração do suinocultor em UT parceiro segue a fórmula descrita a seguir.

$$
\begin{aligned}
& \mathrm{R}=(\mathrm{A} \times \mathrm{B} \times \mathrm{C})+\mathrm{D} \\
& \mathrm{B}=f(\mathrm{CA} \text { média }-\mathrm{CA} \text { lote }) \text { ou mínimo de } 2,5 \%
\end{aligned}
$$

Em que:

$\mathrm{R}=$ remuneração $(\mathrm{R} \$)$

$\mathrm{A}=$ peso das carcaças entregues $(\mathrm{kg})$

5 Este preço da carcaça $(\mathrm{R} \$ / \mathrm{kg})$ está relacionado ao preço do suíno vivo acima citado. 
$\mathrm{B}=$ parcela do peso das carcaças entregues a ser recebida pelo suinocultor (\%), calculado como uma função a partir dos diferencias de conversão alimentar (CA)

CA lote $=$ conversão alimentar do lote entregue para abate

CA média = conversão alimentar média de todos os parceiros

$\mathrm{C}=$ preço de referência $(\mathrm{R} \$ / \mathrm{kg})$

$\mathrm{D}=$ bonificação $(\%)$

\subsection{Cláusulas sobre Especificações Técnicas}

A principal especificação técnica, presente em todos os contratos analisados, ocorre através de cláusulas voltadas à padronização dos animais que seguem para engorda ou para o abate, tais como definições de faixas de peso, limites de idade, períodos de terminação e prazo limite de povoamento entre os lotes (entre 21 e 30 dias). Destaca-se que não há uniformidade nestes parâmetros entre os contratos, nem tampouco entre as agroindústrias. Além disso, assim como ocorre para as definiçóes de volume e remuneração, abrem a possibilidade de estender estes prazos e parâmetros por questões sanitárias, ambientais e de mercado.

Nos contratos em UPL as especificações técnicas dão atenção especial à genética, definindo sua origem, taxa de reposição (de $15 \%$ a $40 \%$ para fềmeas e até $50 \%$ para machos), metas para produtividade das matrizes e a proibição de utilizar animais gerados pelo próprio suinocultor como reprodutores. Entre as UTs em parceria as especificações técnicas voltam-se à nutrição, definindo jejum pré-abate, alimentação diferenciada, restrição alimentar e, também, os prazos para retirada de medicamentos. Assim, entre as UPLs predomina a preocupação com a genética, fator determinante do desempenho de todo o processo produtivo. Entre as UTs esta questão se resolve através das cláusulas de exclusividade no fornecimento de leitões (ver a seguir), predominando as preocupações com o estágio de abate e processamento, como é o caso dos resíduos de medicamentos nos alimentos e a pesagem de animais com ração não absorvida (não transformada em carne).

Tanto em UPL quanto em UT são poucos os contratos que têm cláusulas para definir padrôes para as instalações, o carregamento de animais e o alojamento ou carregamento dos leitôes separados por sexo, peso ou origem. Quase todos remetem esses temas à orientação técnica e às decisões do suinocultor. É importante destacar que nenhum dos contratos analisados define especificações técnicas voltadas para o meio ambiente. Assim como no item anterior, o contrato em CC também estabelece poucas provisões quanto às especificações técnicas, não sendo abordado em detalhes. 


\subsection{Cláusula sobre Monitoramento e Informações}

O principal instrumento de monitoramento e transmissão de informações é a assistência técnica, prevista na maioria dos contratos, e amparada pela cláusula que estabelece livre e permanente acesso da agroindústria às instalações. Além disso, tendo em vista a constante preocupação com a sanidade dos rebanhos, todos os contratos em UPL e metade dos contratos de parceria em UT prevêem que o suinocultor deve comunicar imediatamente qualquer anormalidade na sanidade e na mortalidade dos animais. Também freqüente entre os contratos são as cláusulas sobre identificação e registros, tais como o acompanhamento dos lotes de animais em terminação através de fichas de desempenho, o acompanhamento dos reprodutores através de fichas individuais e a identificação de leitões e reprodutores através de tatuagem, mossa e outros tipos de marcação. Poucos contratos remetem à necessidade de informar antecipadamente a programação de compra e venda de animais, grãos e insumos. Apenas dois contratos analisados prevêem a possibilidade de auditorias e de coleta de amostras de animais, água e insumos para análise laboratorial, medidas que visam monitorar resíduos na carne.

\subsection{Clánsulas sobre Prazos, Exclusividade, Garantias e Penalidades}

As cláusulas que estabelecem exclusividade de compra, venda e fornecimento de leitões, reprodutores, ração e demais insumos aparecem em quase todos os contratos. Em conjunto com as cláusulas de volume, permitem melhor coordenação da quantidade produzida. Além disso, são formas de garantir qualidade, uniformidade e rastreabilidade dos animais. Esta cláusula também abre a possibilidade para a regulação do contrato em função das condições de mercado. As garantias formais são definidas por um conjunto de instrumentos. No caso da agroindústria que fornece animais e insumos (através de entrega ou de venda à vista e a prazo) utiliza-se sobretudo a figura do fiel depositário e assinatura de nota promissória, Cédula do Produtor Rural (CPR), garantias em bens, co-responsabilidade do cônjuge e autorização para obtenção de crédito rural em nome do suinocultor. Por sua vez, o suinocultor tem a garantia de venda, mas poucos contratos garantem o rendimento do suinocultor através de um piso para a remuneração ou indenização por problemas sanitários.

Os contratos têm prazo indeterminado de vigência ou cláusulas que prevêem a possibilidade de renovação automática. Todos definem condicionantes e prazos de aviso prévio para a rescisão contratual, geralmente associada ao não cumprimento de cláusulas, desacordo com a legislação ambiental e sanitária e baixo desempenho. A maioria também prevê a possibilidade de aplicação de multas sobre algum indicador de valor ou volume da transação. Poucos abrem a possibilidade de revisão e ajustes periódicos 
das tabelas de preços, prazos e desempenho. Na Tabela 6 apresenta-se a distribuição de freqüência das cláusulas nos 12 contratos analisados. TABELA 6 - OCORRENCIA DE CLÁUSULAS POR TEMA E SUBTEMA, NOS
CONTRATOS ANALISADOS

\begin{tabular}{|c|c|c|c|c|c|c|}
\hline \multirow{2}{*}{ Tema } & \multirow{2}{*}{ Subtema } & $\mathrm{CC}$ & UPL & UT & \multicolumn{2}{|c|}{ Todos } \\
\hline & & $(n=1)$ & $(n=5)$ & $(n=6)$ & \multicolumn{2}{|c|}{$(n=12)$} \\
\hline \multirow{4}{*}{$\begin{array}{l}\text { Obrigações e } \\
\text { prerrogativas da } \\
\text { agroindústria }\end{array}$} & Fornecer leitões, reprodutores, ração e insumos & 1 & 3 & 6 & 10 & $83 \%$ \\
\hline & Prestar assistência técnica & 1 & 4 & 4 & 9 & $75 \%$ \\
\hline & Transporte de animais e insumos & & 5 & 4 & 9 & $75 \%$ \\
\hline & Programação de carregamento dos animais & & 4 & 4 & 8 & $67 \%$ \\
\hline \multirow{4}{*}{$\begin{array}{l}\text { Obrigações e } \\
\text { prerrogativas do } \\
\text { suinocultor }\end{array}$} & \multirow{4}{*}{$\begin{array}{l}\text { Prover mão-de-obra seguindo orientações técnicas } \\
\text { Prover instalações, sua manutenção e água e } \\
\text { energia } \\
\text { Atender a legislação ambiental e o bem-estar animal } \\
\text { Acompanhamento da pesagem e coleta de } \\
\text { amostras }\end{array}$} & 1 & 5 & 6 & 12 & $100 \%$ \\
\hline & & 1 & 5 & 6 & 12 & $100 \%$ \\
\hline & & 1 & 5 & 5 & 11 & $92 \%$ \\
\hline & & & 2 & 1 & 3 & $25 \%$ \\
\hline \multirow{2}{*}{ Volume } & Define volume de produção e alojamento & 1 & 4 & 5 & 10 & $83 \%$ \\
\hline & Define limites de variação no volume ou alojamento & & 3 & & 3 & $25 \%$ \\
\hline \multirow{6}{*}{ Remuneração } & Define base de cálculo (peso de carcaça ou vivo) & 1 & 4 & 5 & 10 & $83 \%$ \\
\hline & Define cálculo da bonificação & & 4 & 4 & 8 & $67 \%$ \\
\hline & Explicita forma de remuneração & & 4 & 3 & 7 & $58 \%$ \\
\hline & Define preço de referência & & 5 & 2 & 7 & $58 \%$ \\
\hline & Define prazo de pagamento & & 1 & 3 & 4 & $33 \%$ \\
\hline & Considera o desempenho relativo & & & 2 & 2 & $17 \%$ \\
\hline \multirow{7}{*}{$\begin{array}{l}\text { Especificações } \\
\text { técnicas }\end{array}$} & Define faixas de peso, idade e produtividade & 1 & 5 & 6 & 12 & $100 \%$ \\
\hline & Define jejum ou alimentação diferenciada & & 1 & 5 & 6 & $50 \%$ \\
\hline & Define origem e taxa de reposição da genética & & 5 & & 5 & $42 \%$ \\
\hline & Define vacinas, medicamentos e outros insumos & & 3 & 2 & 5 & $42 \%$ \\
\hline & Define intervalo de cobertura e povoamento & & 1 & 3 & 4 & $33 \%$ \\
\hline & $\begin{array}{l}\text { Define alojamento separado por sexo, peso ou } \\
\text { origem }\end{array}$ & & 1 & 2 & 3 & $25 \%$ \\
\hline & Define padrão para carregamento de animais & & 2 & 1 & 3 & $25 \%$ \\
\hline \multirow{3}{*}{$\begin{array}{l}\text { Garantias e } \\
\text { exclusividade }\end{array}$} & \multirow{3}{*}{$\begin{array}{l}\text { Estabelece exclusividade de compra e venda } \\
\text { Estabelece figura do fiel depositário e garantias } \\
\text { reais } \\
\text { Estabelece proteção para vazio sanitário }\end{array}$} & 1 & 5 & 5 & 11 & $92 \%$ \\
\hline & & & 4 & 5 & 9 & $75 \%$ \\
\hline & & & 1 & 3 & 4 & $33 \%$ \\
\hline \multirow{6}{*}{$\begin{array}{l}\text { Monitoramento e } \\
\text { informações }\end{array}$} & \multirow{2}{*}{$\begin{array}{l}\text { Acompanhamento através da assistência técnica } \\
\text { Estabelece livre e permanente acesso às insta- } \\
\text { lações }\end{array}$} & & 5 & 4 & 9 & $75 \%$ \\
\hline & & & 4 & 4 & 8 & $67 \%$ \\
\hline & \multirow{2}{*}{$\begin{array}{l}\text { Estabelece identificação e ficha dos animais } \\
\text { Estabelece comunicação imediata de anormali- } \\
\text { dades }\end{array}$} & & 4 & 4 & 8 & $67 \%$ \\
\hline & & & 4 & 3 & 7 & $58 \%$ \\
\hline & \multirow{2}{*}{$\begin{array}{l}\text { Estabelece programação de compra e venda } \\
\text { Estabelece coleta e análises laboratoriais de } \\
\text { amostras }\end{array}$} & 1 & 2 & 2 & 5 & $42 \%$ \\
\hline & & & & 2 & 2 & $17 \%$ \\
\hline \multirow{4}{*}{$\begin{array}{l}\text { Prazos, penali- } \\
\text { dades e rescisão }\end{array}$} & Define condições de aviso prévio e rescisão & 1 & 5 & 6 & 12 & $100 \%$ \\
\hline & Define multas & & 5 & 4 & 9 & $75 \%$ \\
\hline & Define prazo de vigência limite & 1 & 2 & 2 & 5 & $42 \%$ \\
\hline & Prevê revisão e ajustes periódicos do contrato & & 2 & 1 & 3 & $25 \%$ \\
\hline
\end{tabular}

Fonte: elaborado pelos autores. 


\section{DINÂMICA DA TRANSAÇÃO ENTRE SUINOCULTORES E AGROINDÚSTRIAS}

A integração da produção suinícola remonta ainda às décadas de 1960 e 1970, acompanhando de forma mais tímida a evolução na organização da avicultura industrial no Sul do País. A introdução dos contratos na suinocultura é posterior à organização das integrações, mas remonta ainda à década de 1970 (Belato,1985; Altmann, 1997). Entretanto, a partir das entrevistas, acredita-se que a sua generalização na suinocultura de Santa Catarina tenha ocorrido a partir da segunda metade da década de 1990, concomitante ao processo de aumento de escala e desmembramento dos estabelecimentos em ciclo completo para unidades especializadas, seja na produção de leitões, seja de terminação (Miele, 2006).

\subsection{Mudanças nos contratos e na assistência técnica}

O início da integração ocorreu com os estabelecimentos em CC, com a única exigência de exclusividade no fornecimento de ração pelas agroindústrias, a qual foi sendo ampliada para a genética e alguns insumos. As entrevistas com os suinocultores apontaram para o aumento das exigências e especificaçóes técnicas tanto nos contratos como através das orientaçóes da assistência técnica. Na opinião dos 19 suinocultores entrevistados os contratos não mudam com muita frequiência, apesar de terem evoluído. De fato, entre os 12 contratos analisados, apenas quatro sofreram alterações através de adendos ou aditivos. Para os suinocultores entrevistados, as mudanças são mais percebidas na maneira de trabalhar das agroindústrias e na relação com a assistência técnica, visto que a maioria das exigências não são escritas. Em geral, as mudanças apontadas pelos suinocultores estão alinhadas com as mudanças detectadas na análise dos contratos, quais sejam: a inclusão de cláusulas sobre uso e restrição de medicamentos e vacinas, a responsabilização do suinocultor em relação aos dejetos, com a necessidade de adequação à legislação ambiental e, também, mudanças na remuneração do suinocultor ou na divisão de responsabilidades com implicações nos seus custos.

Entretanto, deve-se ressaltar que parte das mudanças verificadas nas alterações contratuais são exemplos de maior complexidade e detalhamento de especificações técnicas e regras de remuneração, apontando para um processo de aprendizagem e acúmulo de experiência por parte das agroindústrias na elaboração e negociação de contratos. Por outro lado, os suinocultores independentes também citaram exigências e restrições semelhantes aos integrados. Ponderaram que são questóes postas pelo mercado ou pela legislação, que devem ser cumpridas por todos os suinocultores, independente do seu vínculo. 
Quando perguntados sobre as mudanças futuras nos contratos ou na maneira de trabalhar das agroindústrias e na relação com a assistência técnica, muitos suinocultores referiram-se a desejos e reivindicações, que não necessariamente apontam para tendências. Nesse sentido, os principais itens citados foram a divisão de responsabilidade no manejo e distribuição de dejetos, a maior estabilidade nos preços do suíno e dos grãos e o acesso a benefícios, como auxílio ou plano de saúde (já obtido pelos produtores de aves), seguro contra acidentes e férias remuneradas. Além destas questões, que remetem para um problema agrário não relacionado à posse da terra mas à qualidade da relação de trabalho, citaram a tendência de aumento das exigências e restrições, sobretudo na parte ambiental e de segurança dos alimentos (rastreabilidade).

\subsection{O Processo de Negociação e Seleção de Novos Suinocultores}

Entre a maioria dos suinocultores entrevistados, o processo de negociação se dá de forma individual e através da assistência técnica, que em determinadas situações remete a questão a um nível de supervisão ou chefia. Entre os cooperados foi apontada a prática de reunião de suinocultores com a assistência técnica. Entre os mini-integradores ou entre a maioria dos estabelecimentos em CCs há a negociação direta e individual, geralmente com níveis hierárquicos acima da assistência técnica, chegando até ao proprietário do frigorífico em um dos casos. Isso depende do porte da agroindústria, mas ocorre sobretudo porque estes suinocultores conseguem reunir volumes consideráveis de animais para abate ou porque prestam serviço de transporte de animais, o que facilita o contato direto com a agroindústria.

Mesmo entre os suinocultores que não são cooperativados, há experiências associativas para negociar de forma conjunta reivindicações junto à agroindústria, com a mobilização de parcela significativa dos seus integrados. São iniciativas como o Clube do Leitão, constituído por integrados da Perdigão, a Associação das UPLs e a Associação de Parceiros da Sadia, e ações da ACCS. Entretanto, os suinocultores entrevistados se consideram em geral pouco associativos, em função de fatores desmobilizadores como a distância, a ausência de organização em todos os municípios, a mentalidade de subordinação e acomodação e a baixa capacidade de interlocução. Além disso, acreditam que uma postura excessivamente contestadora pode levar à suspensão temporária ou ao desligamento da integração.

Soma-se a isto a influência de fatores subjetivos não restritos à esfera econômica ou técnica, mas de natureza interpessoal, que dependem mais da postura do técnico do que da agroindústria. Enquanto uns citam que a maioria das exigências são feitas "na pressão", outros ponderam que há margem de negociação quando o suinocultor se posiciona de maneira firme ou quando desenvolve uma boa relação com o técnico. 
Também foi citado que o grau de endividamento influencia na negociação, visto que "quando o chiqueiro está pago" há a possibilidade de encerrar temporariamente as atividades caso as condições não sejam vantajosas.

Entre os estabelecimentos em CC e os independentes entrevistados relatou-se haver liberdade nas práticas de produção e gestão, com a possibilidade de negociação em todas as dimensões da transação. O mesmo ocorre entre os mini-integradores, sobretudo em função da escala. Entre os estabelecimentos integrados (com ou sem contrato), a maioria considera que há maior margem de negociação apenas em torno de questôes relativas à qualidade dos reprodutores, leitões e insumos fornecidos. Isso ocorre, sobretudo, porque há a possibilidade (autorizada ou vedada nos contratos) de procurar outros fornecedores. Além disso, metade dos suinocultores entrevistados considera que pode haver negociação em torno das especificações para equipamentos e instalações, bem como nas práticas de produção e gestão do estabelecimento. Quanto à remuneração, a maioria considerou não haver margem de negociação, em que pesem as iniciativas associativas acima descritas.

Tanto integrados quanto independentes relataram haver uma relação de confiança entre eles e a agroindústria, com o cumprimento de acordos tácitos e contratos até mesmo nos períodos de crise ou de aquecimento do mercado. Entretanto, e apesar de não ser a regra entre os entrevistados, deve-se ressaltar os relatos de quebras contratuais ou de acordos. Do lado da agroindústria, foram citados problemas com a qualidade dos leitões, dos reprodutores (genética) e da ração, o sobrealojamento de animais, o alongamento no período de terminação (implicando elevação da conversão alimentar e da mortalidade), o excesso de condenações de carcaças e atrasos no carregamento e entrega de animais e ração. Do lado do suinocultor, foram citados problemas relacionados à exclusividade, com a venda de leitões ou animais terminados para terceiros, o desvio de leitôes para a terminação própria, a aquisição de genética, ração e insumos de origem não autorizados, o desvio de ração e medicamentos para outras finalidades (como é o caso dos bovinos de leite), e o cumprimento parcial de certas especificações.

Do ponto de vista daqueles suinocultores que estão em processo de seleção para ingressar nas integraçóes, as principais exigências relatadas pelos suinocultores entrevistados são o atendimento à legislação ambiental e a definição de uma escala mínima de produção cada vez maior. Além disso, também citaram a necessidade de modernizar as instalações e adequá-las ao padrão da agroindústria, bem como a existência de restrições à entrada ou permanência de suinocultores em CC. Por fim, ressalta-se que aqueles suinocultores com sistemas especializados (UPL e UT), que atuam através das integrações e amparados por contratos formais apresentaram menor variação no número de agroindústrias com as quais transacionaram. Isso é um indicador de que 
entre esse tipo de suinocultor há maior continuidade da transação e, provavelmente, menor quebra contratual.

\subsection{Evolução Recente das Formas de Coordenação na Suinocultura de Santa Catarina}

Os contratos são a forma predominante de organização da produção em Santa Catarina, seguidos pela integração através dos programas de fomento pecuário das cooperativas e de empresas agroindustriais e, por último, pela suinocultura independente (Tabelas 3, 4 e 5). Entre as empresas agroindustriais analisadas prevalece o uso de contratos de parceria para as UTs e de contratos de compra e venda para as UPLs. Este sistema especializado-contratualizado tem crescido em importância no período em análise e é complementado pela suinocultura independente e por alguns poucos estabelecimentos em CC integrados sem contrato. Nos programas de fomento fora das cooperativas, o crescimento dos abates também ocorreu a partir de esquemas de parceria sem contrato.

Além de apontar para a continuidade do processo de desmembramento dos estabelecimentos em CC, essa tendência aponta para a transferência de riscos e margens para a agroindústria, com a substituição de contratos de compra e venda por contratos de parceria, no qual o suinocultor não detém a propriedade de animais e ração. Os dados analisados mostram que esta tendência não se aplica aos estabelecimentos em UPL, que mantém a propriedade dos reprodutores (ver participação dos contratos de compra e venda no alojamento de matrizes, Tabela 5). Entretanto, alguns entrevistados apontaram para uma nova tendência de substituição por contratos de comodato, em que a propriedade dos reprodutores e, portanto o risco e as margens, também são transferidos à agroindústria.

Entre as cooperativas, verifica-se a maior participação dos contratos de compra e venda em detrimento dos de parceria na fase de terminação. Verifica-se, também, a inserção das UPLs em programas de fomento vinculados à origem da genética sem um contrato formal. Há, portanto, diferenças na repartição de riscos e nas escolhas produtivas em relação às demais empresas agroindustriais. O processo recente de aumento da escala e especialização entre os suinocultores catarinenses (Heiden et al., 2006; Miele, 2006) ocorreu de forma mais branda no sistema cooperativo, que manteve em seus programas de fomento suinocultores com escala de produção inferior à dos demais integrados, assim como uma expressiva participação dos estabelecimentos em CC. O mercado spot manteve sua participação nos abates no período analisado. Composto basicamente pelos mini-integradores, volta-se para atender não apenas pequenos abatedores ou mercados do centro do País, mas sobretudo a demanda das prin- 
cipais agroindústrias. A esse papel de ajuste na oferta de animais soma-se a absorção de suinocultores excluídos dos circuitos de integração (empresas e cooperativas).

\section{CONSIDERAÇÕES FINAIS}

O presente trabalho descreveu as principais características da suinocultura integrada (com e sem contrato) e da suinocultura independente. Para tanto, abordou as relaçôes a montante e a jusante do estabelecimento rural, indicando a divisão de responsabilidades técnicas e financeiras entre suinocultores e agroindústrias. Esta divisão tem implicações para outras áreas de pesquisa em economia e gestão, bem como para a assistência técnica, como é o caso do cálculo dos custos de produção e da análise da repartição do risco entre estes agentes. Com base nessa caracterização e nos dados disponíveis, observou-se que a integração com o uso de contratos é predominante em Santa Catarina, mas que também há expressiva participação dos estabelecimentos integrados sem contratos, inseridos através de programas de fomento pecuário, sobretudo entre as cooperativas. Esse resultado aponta para a possibilidade de crescimento no uso dos contratos, mas, por outro lado, para existência de formas de coordenação da cadeia produtiva sem o uso de tais instrumentos jurídicos, e baseadas apenas em instrumentos administrativos de incentivo e controle como a ação da assistência técnica e dos esquemas de logística. Além disso, destacou as diferenças entre a terminologia empregada pelos agentes da cadeia produtiva e a terminologia teórica. Essas diferenças não são incompatíveis, mas exigem maior esforço por parte daqueles que estudam o tema.

Os contratos analisados e as regras que norteiam os programas de fomento pecuário diferem em função da agroindústria, do sistema de produção e do ano, mas têm algumas características comuns. Todos delimitam claramente a divisão de responsabilidades entre os suinocultores e as agroindústrias e se reportam a condiçôes de mercado para regular variações excessivas nos volumes ou para obter um parâmetro de preços. Em um contrato típico a agroindústria assume os riscos associados a variações nos preços dos grãos, mas transfere os riscos ambientais para o suinocultor. Apesar desses traços comuns, há grande heterogeneidade nestes instrumentos. De um lado há aqueles mais simples, voltados quase que exclusivamente ao estabelecimento de garantias formais de compra e venda e de direitos de propriedade sobre os plantéis, a ração e demais insumos. Por outro lado, há contratos mais complexos que, além das garantias, voltam-se para a gestão da cadeia produtiva formalizando esquemas de incentivo, o papel da assistência técnica como agente de monitoramento e controle e detalhando especificações técnicas. 
A integração da produção volta-se para objetivos econômicos e de eficiência técnica. Em primeiro lugar, verifica-se a busca pela redução do risco de variações excessivas no volume e na qualidade dos animais disponíveis para o abate, reduzindo assim a ociosidade das plantas industriais e os custos de adequação de equipamentos (setup), aumentando a uniformidade nos produtos finais e otimizando os circuitos logísticos (Altmann, 1997). Em paralelo, esses esforços reduzem o risco do suinocultor porque estabelecem garantias de escoamento da produção. Em relação a variações inesperadas nos preços dos grãos e insumos, a divisão de responsabilidades transfere o risco para a agroindústria, sobretudo nos contratos de parceria e comodato. Entretanto, em função das condições de poder de mercado, deve-se considerar que esses riscos podem ser transferidos parcial ou totalmente de volta aos suinocultores em períodos de crise, através da renegociação das tabelas de remuneração e queda no preço de referência. Além disso, o risco ambiental é totalmente transferido ao suinocultor. Esses objetivos também aparecem na estrutura de incentivos existente no método de cálculo, que utiliza critérios de desempenho baseados na eficiência produtiva, na padronização, na realização de investimentos específicos e na aceitação de boas práticas de manejo e gestão. A assistência técnica tem papel central na integração, permitindo não apenas o melhor aproveitamento e adoção de novas tecnologias, como, principalmente, o monitoramento da transação e dos critérios de incentivo.

O aumento de escala e da especialização na suinocultura industrial verificado na última década ocorre concomitantemente ao crescimento da integração e, mais particularmente, dos contratos nas empresas agroindustriais. Entretanto, essas mudanças vêm ocorrendo também no sistema cooperativo e entre os independentes, mesmo que de forma menos intensa (Miele, 2006; Miele; Waquil, 2006). Assim, as imposições da crescente tecnificação e as limitações de recursos entre os suinocultores do Oeste de Santa Catarina (terra, mão-de-obra e capital) parecem estar na origem dessas tendências, não havendo um sentido claro de causalidade. $\mathrm{O}$ mesmo não pode ser dito do desmembramento dos estabelecimentos em CC para a produção em dois estágios (UPL + UT), que surge como uma opção estratégica das empresas agroindustriais.

Para concluir,

"se são os individuos que tomam decisões, então é provável que a 'estrutura' organizacional (e outras caracteristicas) determinem uma diferença. As influências sobre os individuos não são apenas aquelas externas à organização, mas também (e muito particularmente) as internas" (Leibenstein, 1978, p. 82, traduzido pelos autores). 


\section{REFERENNCIAS BIBLIOGRÁFICAS}

Alchian, B.; Demsetz, H. Production, information costs and economic organization. American Economic Review, n. 62, p. 777-795, 1972.

Altmann, R. A agricultura familiar e os contratos: reflexões sobre os contratos de integração, a concentração da produção e a seleção de produtores. Florianópolis: Ed. Palotti, 1997. 112p.

Arrow, J. K. The economics of agency. In: Pratt, J. W., Zeckhauser, R. (Eds.). Principals and agents: the structure of business. Boston: Harvard Business School Press, 1991.

Associação Brasileira da Indústria Produtora e Exportadora de Carne Suína. Estatísticas. Disponível em: < http://www.abipecs.org.br >. Acesso em: 20 abr. 2006.

Barkema, A. D. New Roles and Alliances in the US Food System. Paper presented at the Spring Meeting of the Federal Reserve System. Committee on Agriculture and Rural Development. Kansas City, 1993. (mimeo)

Barkema, A.; Cook, M. L. The changing US pork industry: a dilemma for public policy. Economic Review. Kansas City: Federal Reserve Bank of Kansas City, p. 49-65, 1993.

Belato, D. Os camponeses integrados. 1985. 441 p. Dissertação (Programa de PósGraduação em História) - Universidade de Campinas, Campinas, 1985.

Blois, K. J. Vertical Quasi-Integration. Journal of Industrial Economics, 3, 1972.

Eisendhart, K. E. Agency theory: an assessment and review. Academy of Management Review, v. 14, p. 57-74, 1989.

Farina, E.M.M.Q.; Azevedo, P.F; Saes, M.S.M. Competitividade: mercado, Estado e organizações. São Paulo: Singular, 1997. 286p.

Frank, S. D.; Henderson, D. R. Transaction Cost as Determinants of Vertical Coordination in the U.S. Food Industries. American Journal of Agricultural Economics, november, 1992.

Goldberg, R. A. Agribusiness Coordination: a systems approach to the wheat, soybean, and Florida orange economies. Division of Research. Graduate School of Business and Administration. Harvard University, 1968. 256p.

Guivant, J.; Miranda, C. As duas caras de Jano: agroindústrias e agricultura familiar frente à questão ambiental. Cadernos de Ciência e Tecnologia, v. 16, n. 3, p.85$128,1999$.

Heiden, F.; Reiter, J. W.; Echeverria, L. C.; Mondardo, M. Indicadores da evolução do setor agrícola catarinense - dados preliminares. Grupo de limpeza do LAC, agroindicadores. Disponível em: < http://cepa.epagri.sc.gov.br/ > Acesso em: 30 mar 2006. 
Joskow, P. L. The new institutional economics: alternatives approaches. Journal of Institutional and Theoretical Economics, v. 151, n. 1, p. 248-259, 1995.

Klein, B. Contracts and incentives: the role of contract terms in assuring performance. In: Werin, L.;Wijkander, H. (Eds.), Contract Economics. Cambridge, MA: Basil Blackwell, 1992. Cap. 6, p. 149-173.

; Crawford, R. A.; Alchian, A. A. Vertical integration, appropriable rents, and the competitive contracting process. Journal of Law and Economics, n. 21, p. 297-326, 1978.

Labonne, M. Sur le concept de filière en économie agro-alimentaire. Montpellier: Institut National de Recherche Agronomique, Laboratoire d'Economie et Sociologie Rurales, 1985. Réunion MSA - CEGET, 13-14 juin 1985. p.1-11.

Lawrence, J. D.; Schroeder, T. C.; Hayenga, M. L. Evolving producer-packer-customer linkages in the beef and pork industries. Review of Agricultural Economics, v. 23, n. 2 , p. $370-385,2001$.

; Rhodes, V. J.; Grimes, G. A.; Hayenga, M. L. Vertical coordination in the US pork industry: status, motivations and expectations. Agribusiness, v.13, n.1, p. 21-31, 1997.

Leibenstein, H. Teoría micro-micro, comercio agente-agente y eficiencia-X. In: Dopper, K. (Coord.). La economía del futuro. Hacia un nuevo paradigma. México: Fondo de Cultura Económica, 1978. Cap. 3, p. 78-98.

Mariotti, S.; Cairnaca, G. C. The Evolution of Transaction Governance in the textileClothing Industry. Journal of Economic Beabaviour and Organization, v. 7, n. 4, p. $351-374,1986$.

Martinez, S. W.; Zering, K. Pork quality and the role of market organization. [S.l.]: U.S. Department of Agriculture, 2004. 45p. (Economic Research Service. Agricultural Economic Report, 835). Disponível em: < http://www.ers.usda.gov>. Acesso em: 09 ago 2005.

Martinez, S. W. Vertical coordination in the pork and broiler industries: implications for pork and chicken products. [Sl.]: U.S. Department of Agriculture, 1999. 43p. (Economic Research Service. Agricultural Economic Report, 777). Disponível em: <http://www.ers.usda.gov>. Acesso em: 09 ago 2005.

Menard, C. On clusters, hybrids and other strange forms: the case of the french poultry. Journal of Institutional and Theoretical Economics. v. 152, n. 11, p.154 - 183, 1996.

Miele, M. Contratos, especialização, escala de produção e potencial poluidor na suinocultura de Santa Catarina.2006, 278p. Tese (PPG-Agronegócios) - UFRGS, Porto Alegre, 2006.

; Waquil, P. D. Cadeia produtiva da carne suína. Revista de Política Agrícola, v. XV, n. 4, 2006. 
Pratt, J. W.; Zeckhauser, R. Principals and agents: an overview. In: Pratt, J. W.; Zeckhauser, R. (Eds.). Principals and agents: the structure of business. Boston: Harvard Business School Press, 1991.

Rabobank. Internationalizing pork companies. The Hague, Netherlands: Rabobank Food \& Agribusiness Research, 2001. 31 p.

Santini, G. A.; Souza Filho, H. M. Mudanças tecnológicas em cadeias agroindustriais: uma análise dos elos de processamento da pecuária de corte, avicultura de corte e suinocultura In: CONGRESSO DA SOCIEDADE BRASILEIRA DE ECONOMIA RURAL, 42, 2004, Cuiabá. Anais. Cuiabá, SOBER, 2004a. p.1-12.

Sindicato das Indústrias de Carnes e Derivados no Estado de Santa Catarina. Plantéis de suinos com base nas informações das empresas sob SIF. Dez. 2001 a Out. 2005 (Planilha eletrônica)

Sporleder, T. L. Managerial economics of vertically coordinated agricultural firms. American Journal of Agricultural Economics, v. 74, n. 5, p.1226-1231, 1992.

Vukina, T. The Relationship between Contracting and Livestock Waste Pollution. Review of Agricultural Economics, v. 25, n. 1, p. 66-88, 2003.

Weydmann, C. L. O padrão concorrencial na agroindústria suína e as estratégias ambientais. In: Guivant, J.; Miranda, C. (Org.). Desafios para o desenvolvimento sustentável da suinocultura. Chapecó, [s.n.], 2004, v. 1, p. 173-199.

Williamson, O. Comparative Economic Organization: The Analysis of Discrete Structural Alternatives. Administrative Science Quarterly, v. 36, p.269-296, 1991.

. Transaction-cost Economics: The Governance of Contractual Relations. Journal of Law and Economics, v. 22, p.233-262, 1979.

Yin, R. K. Estudo de caso: planejamento e métodos. 2. ed. Porto Alegre: Bookman, 2001. 205p.

Zylbersztajn, D. Papel dos contratos na coordenação agro-industrial: um olhar além dos mercados. Revista de Economia e Sociologia Rural. Brasília, v. 43, n. 03, p. 385-420, 2005.

; Farina, E. M. M. Q. Agry-system Management. Recent Developments and Applicability of the Concept. In: Ziggers, G. W.; Trienkens, J. H.; Zuurbier, P. J. P. Proceedings of the Third International Conference on Chain Management in Agribusiness and the Food Industry, Ede, May, 1998. 